\title{
Psychodermatology: a molecular link between psoriasis and anxiety disorder
}

\author{
Eugene Klimov ${ }^{1,2,3}{ }^{凶}$, Artemii Tretiakov¹, Olga Rudko ${ }^{1}$, Anna Soboleva $^{4}$, Ivan Danilin ${ }^{5}$, Irina Korsunskaya ${ }^{4}$, Vladimir \\ Sobolev $2,4,6$
}

\begin{abstract}
This article describes premises for the development of psychodermatology. An analysis of research literature and data is presented based on the example of psoriasis and anxiety disorder. Protein molecules with altered concentrations in patients with psoriasis and anxiety disorder compared to controls are identified (chemokine [C-C motif] ligand 2, corticotropin-release hormone, growth hormone 1, leptin, and tumor necrosis factor with increased concentration and brain-derived neurotrophic factor with decreased concentration). All molecules are secretory peptides. In the future, the information obtained may make it possible to pursue an in-depth study of the molecular mechanisms underlying psychodermatology.
\end{abstract}

Keywords: psychodermatology, psoriasis, anxiety disorder, signaling pathways, peptides

Received: 30 March 2018 | Returned for modification: 25 May 2018 | Accepted: 26 June 2018

\section{Introduction}

Psychodermatology is an interdisciplinary field combining psychiatry and dermatology. Psychodermatology studies links between skin and mental diseases that occasionally develop in the same patient (1).

Although psychodermatology has only recently gained recognition among researchers, the connection between dermatological and mental disorders first appeared in the literature in the nineteenth century (2). In his 1850 book Diseases of the Skin, Erasmus Wilson characterized several diseases, including alopecia areata (spot baldness), skin hypopigmentation, itching (pruritus), and delusional parasitosis, as "cutaneous neuroses." This book is considered the beginning of modern psychodermatology (2).

In the early twentieth century, psychodermatological problems rarely appeared in the literature. In 1925, Joseph Klauder highlighted the importance of psychotherapy in the treatment of skin diseases (2). The authors of 1930 article "The effect on the skin of emotional and nervous states" summarized the information on the subject and raised several psychodermatological problems as well (3). However, until the mid-twentieth century, there were no notable studies in psychodermatology (2).

Starting in the 1960s and mostly in recent decades, interest in psychodermatology increased significantly. In spite of the fact that several psychodermatology textbooks are available (4), recent polls have shown that researchers and medical doctors do not have sufficient knowledge of this field. Whereas $42 \%$ of dermatologists and $22 \%$ of psychiatrists consider themselves capable of diagnosing psychodermatological diseases (1), only $18 \%$ of dermatologists and $21 \%$ of psychiatrists acknowledged understanding what psychodermatology is $(1,5)$.

\section{General tendencies}

Even in the absence of any pathological processes, psychological states may affect skin condition. Blushing due to emotional stress, sweating when anxious, and paleness as a manifestation of fear are good illustrations of this tendency (6). Apart from these shortterm changes, skin condition reflects health condition in general and plays a role in both physical and mental health maintenance (6).

More than a third of patients that suffer from dermatological diseases also have psychological disorders that aggravate their condition $(1,7)$. In many cases, such patients require not only drug treatment, but also psychological or even psychiatric help (4).

The urgency of this problem is determined by a significant number of skin diseases that act in comorbidity with mental disorders. According to Tress et al., mental disorders appear in 35.5\% of dermatological patients (8). The same results were obtained by Picardi et al., who worked on this problem for many years and concluded that in 30 to $40 \%$ of cases dermatological diseases are accompanied by mental pathologies (9).

Skin diseases may provoke mental problems associated with shame, anxiety, or depression (2). For the majority of people, their visual appearance, as well as the appearances of other people, play an important role. Even minor changes in skin condition (e.g., mild acne) can cause significant stress in many people, whereas others cope better with a diagnosis of severe skin disease (10). Psoriasis, vitiligo, acne vulgaris, chronical eczema, acne rosacea, neurofibroma, Darier's disease, and some other diseases that affect the appearance of the skin may also affect the psyche by changing a person's self-image as well as some aspects of his or her social life $(10,11)$. In these situations, psychological diseases may develop secondary to skin diseases. Helping people to understand the real nature of skin diseases and spreading information about them within the society to prevent stigmatization may significantly lower the damage caused by such diseases (10).

The converse situation is possible because skin is often an object of self-harm and destructive behavior for people suffering from psychological problems, which leads to dermatological

${ }^{1}$ Faculty of Biology, Lomonosov Moscow State University, Moscow, Russia. ${ }^{2}$ University Diagnostic Laboratory, Moscow, Russia. ${ }^{3}$ Center for Experimental Embryology and Reproductive Biotechnologies, Moscow, Russia. ${ }^{4}$ Center for Theoretical Problems of Physico-Chemical Pharmacology, Russian Academy of Sciences, Moscow, Russia. ${ }^{5}$ Peoples’ Friendship University of Russia, Moscow, Russia. ${ }^{6}$. I. Mechnikov Research Institute for Vaccines and Sera RAMS, Russia, Moscow. $\bowtie$ Corresponding author: klimov@mail.bio.msu.ru 
symptoms $(2,7)$. Thus, dermatological disease develops secondary to psychological conditions. Patients usually manipulate their skin and its derivatives (nails and hair) to cope with emotions or anxiety. Most commonly affected are those with diagnosed dissociative and obsessive-compulsive disorders (OCD). OCD in particular may lead to self-induced skin diseases, including dermatitis artificialis, skin-picking disorder, nail biting (onychophagy), and hair-pulling disorder (trichotillomania). Moreover, some psychosomatic reactions inherent in the autonomic nervous system and some disruptions in the immune system may lead to symptoms such as pruritus, idiopathic hives, and idiopathic pathological sweating (7).

It is considered that four mental disorders may notably affect skin condition: anxiety, depression, OCD, and psychosis. All of them occur significantly more often in people with skin diseases compared to other mental conditions (1).

Because of poor awareness, dermatologists rarely advise their patients to consult a psychologist or psychiatrist. A poll among dermatologists in the Netherlands revealed that only eight dermatological patients per year are advised to visit a psychologist or psychiatrist (12). This is considered a critical problem because many dermatological diseases are not only aggravated because of stress but may also increase levels of stress, thereby being both a cause of as well as a result of it (13).

The key to successfully treating dermatological disease lies not only in diagnosing the disease, but also in understanding the severity of patients' stress, identifying its causes, and evaluating the quality of their social life. This requires an individual approach to each patient and a combination of not only dermatological but also psychological methods (13).

\section{The link between dermatological diseases and the psyche}

Among its other vital functions, the skin serves as a sensory organ. For instance, it detects and relays changes in the environment, such as information about temperature, tactile sensations, and pain, to the central nervous system. The nervous system responds to these signals by causing changes in the skin such as temporary changes in sweat glands (14). Another important function of the skin is forming a physical and chemical barrier, which protects against mechanical stress, variations in temperature, invasion of microorganisms, chemicals, and radiation (15).

The association between the psyche and skin conditions may be explained by studying the relationships of the neuroendocrine and immune system, or the neuro-immuno-cutaneous endocrine (NICE) system. The hypothesis about the NICE system and the NICE model was first described by O'Sullivan et al. to further explain the relationship between the psyche and the human body (6). It has previously been shown that some inflammatory skin diseases destabilize the NICE system (16).

The correlation between skin and the psyche is not coincidental. As already stated above, the skin condition may reflect the current condition of the body and psyche. During embryogenesis, both the skin and brain develop from the ectoderm, and both have common effector molecules, including neuropeptides, cytokines, and glucocorticoids (6).

\section{Common molecular targets for psoriasis and anxiety disorders as one of the models for psychodermatology}

Psoriasis (psoriasis vulgaris, L40.0) is a chronic inflammatory autoimmune skin disease with a complicated etiology that develops due to both internal (genetic) and external factors. Some researchers suggest that psoriasis is a systemic disease, affecting not only the skin but also various systems and organs (17).

Anxiety disorder (F41.1) is a psychiatric disorder characterized by a sustainable anxiety not caused by any particular objects or situations. Irrational fear of a disease or an accident may be present, as well as some other fears and misgivings $(18,19)$. There are tendencies toward fluctuation and chronification of the disease (20).

In order to reveal possible common molecular pathways in psoriasis and anxiety disorders, we conducted a search of protein molecules that undergo a quantity change during both diseases. We used PathwayStudio 9.0 software with the ResNet 13 database (Elsevier), which contains information from literature available on the internet. To find the proteins with a changed concentration, we used the "common targets" filter and searched only for links of the QuantitativeChange type. For further study, we only chose proteins with altered concentrations in both psoriasis and anxiety disorder. We identified seven proteins with altered concentrations; the results are shown on Figure 1. Next, we analyzed referenced articles in detail. Articles with statistically significant results and reviews with reference to original papers were taken into consideration. This stage eliminated ADIPOQ (adiponectin, $\mathrm{C}_{1} \mathrm{Q}$ and collagen) protein because its concentration is altered in patients with migraine and not in patients with anxiety disorder. The results of the analysis of the articles are provided in Table 1.

As shown in Table 1, all the proteins identified are secretory molecules that participate in various intercellular processes, including metabolism regulation, neuron homeostasis, and immune responses. The same patterns of quantitative changes are described for most of these proteins: they are increased in psoriasis and anxiety disorders compared to normal states, with the exception of brain-derived neurotrophic factor (BDNF), the concentration of which is decreased in psoriasis and anxiety disorders.

Data-mining showed that these peptides can be divided into further groups according to the type of processes they take part in: 1) catabolism: growth hormone 1 (GH1) and leptin (LEP); 2) neuron homeostasis: BDNF; 3) immune response: chemokine (C-C motif) ligand 2 (CCL2) and tumor necrosis factor (TNF); and 4) behavioral reactions: corticotropin-release hormone (CRH).

Among all the peptides found in this study, the most promising is $\mathrm{CRH}$, which is a stress hormone that releases in case of anxiety, fear, or stress. Prolonged exposure to CRH induces depression, anxiety, and insomnia (52). An increased concentration of this peptide in psoriasis and anxiety disorders may be an evidence of similarities in their pathogenesis. The pro-inflammatory role of CRH is noted in many studies, some of which demonstrate increased expression of CRH and CRH-receptor in the affected skin of patients with psoriasis (53). Other molecules may play a role in pathogenesis as well, activating similar pathways in different tissues.

A distinctive feature of the regulatory peptides is pleiotropy, or the ability to affect several different physiological functions. On the other hand, many physiological functions undergo similar changes under the influence of various regulatory peptides. In addition, peptides are capable of mutual regulation of expression. For example, the expression of CRH may be activated by TNF (54), BDNF (55), and LEP (56). CRH, meanwhile, regulates TNF expression (57), BDNF expression (58), and GH1 release (59). According to ResNet13, similar relations exist between other proteins stud- 


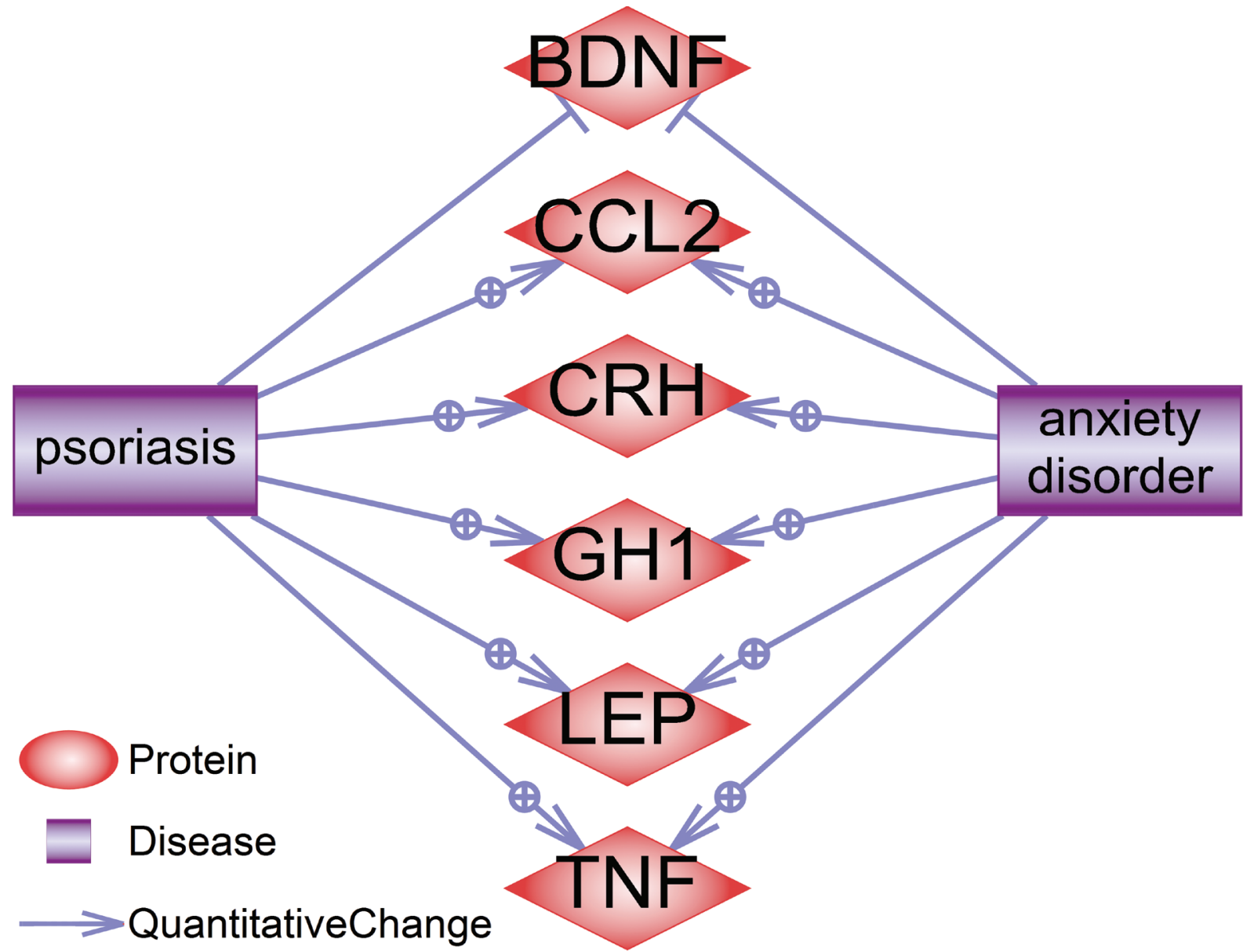

Figure 1 | Proteins with altered expression linked with both psoriasis and anxiety disorders.

Table 1 | Proteins and their links to psoriasis and anxiety disorder in alphabetical order. Functions are listed according to NCBI (https://www.ncbi.nlm.nih.gov/ gene).

\begin{tabular}{|c|c|c|}
\hline Gene, description & Link to psoriasis & Link to anxiety disorder \\
\hline $\begin{array}{l}\text { BDNF (brain-derived neurotrophic factor) } \\
\text { responsible for growth and homeostasis of } \\
\text { brain neurons }\end{array}$ & $\begin{array}{l}\text { Lowered in patients with psoriasis, depression } \\
(21) \text {, chronic stress }(22)\end{array}$ & $\begin{array}{l}\text { Lowered in patients with anxiety disorders } \\
(23-26)\end{array}$ \\
\hline $\begin{array}{l}\text { CCL2 (chemokine (C-C motif) ligand } 2 \text { ) activates } \\
\text { chemotaxis in monocytes and basophils }\end{array}$ & $\begin{array}{l}\text { Significant increase in serum of patients with } \\
\text { psoriasis }(27,28)\end{array}$ & Increased in patients with anxiety disorder (29) \\
\hline $\begin{array}{l}\text { GH1 (growth hormone) required for control of } \\
\text { body height }\end{array}$ & $\begin{array}{l}\text { Increased in patients with skin diseases, } \\
\text { including psoriasis (30) }\end{array}$ & $\begin{array}{l}\text { Increased in patients with stress and anxiety } \\
\text { disorder ( } 31 \text { ) }\end{array}$ \\
\hline $\begin{array}{l}\text { CRH (corticotropin-releasing hormone) is } \\
\text { synthesized in response to stress and stimulates }\end{array}$ & $\begin{array}{l}\text { Significant increase in serum of patients with } \\
\text { psoriasis (32) }\end{array}$ & $\begin{array}{l}\text { Increased in patients with anxiety disorder (31, } \\
33,34)\end{array}$ \\
\hline
\end{tabular}

release of adrenocorticotropin

LEP (leptin) is secreted by adipocytes, regulates Increased in patients with psoriasis (35-42)

fat and energy metabolism, as well as some

endocrine functions and an inflammatory/

immune response

TNF (tumor necrosis factor), a multifunctional proinflammatory cytokine, is involved in the regulation of a variety of cellular and

Significant increase of expression in serum and skin of patients with psoriasis (44-50)
Increased in patients with anxiety disorder (43)

Increased in patients with anxiety disorder and systemic lupus erythematosus (51) physiological processes

ied; for example, GH1 regulates LEP, CCL2, and TNF expression; CCL2 regulates TNF expression; TNF regulates CCL2, BDNF, LEP, and $\mathrm{GH}_{1}$ expression; and LEP regulates BDNF, $\mathrm{CRH}, \mathrm{GH} 1$, and CCL2 expression. Further studies may elucidate the link between the pathogenesis of psoriasis and anxiety disorder.

\section{Conclusion}

This review discusses the relationship between the skin and psy- che, and it identifies possible correlations between the molecular comorbidity of psoriasis and anxiety disorders. The six molecules (BDNF, CCL2, GH1, CRH, LEP, and TNF) considered as common points for both conditions are signaling peptides that can modulate a variety of cellular and physiological processes. This review may elucidate possible factors and processes involved in the pathogenesis of both psoriasis and anxiety disorder, inspiring other researchers to undertake more detailed research on the most important psychodermatological mechanisms. 


\section{References}

1. Leon A, Levin EC, Koo JY. Psychodermatology: an overview. Semin Cutan Medi Surg. 2013;32:64-7.

2. Rodriguez-Cerdeira C. Psychodermatology: past, present and future. Open Dermatol J. 2011;5:21-7.

3. Stokes JH. The effect on the skin of emotional and nervous states: II. Masochism and other sex complexes in the background of neurogenous dermatitis. Arch Derm Syphilol. 1930;25:803-10.

4. Poot F, Sampogna F, Onnis L. Basic knowledge in psychodermatology. J Eur Acad Dermatol Venereol. 2007;21:227-34.

5. Jafferany M, Stoep AV, Dumitrescu A, Hornung RL. Psychocutaneous disorders: a survey study of psychiatrists' awareness and treatment patterns. South Med J. 2010;103:1199-203.

6. O'Sullivan RL, Lipper G, Lerner EA. The neuro-immuno-cutaneous-endocrine network: relationship of mind and skin. Arch Dermatol. 1998;134:1431-5.

7. Gordon-Elliott JS, Muskin PR. Managing the patient with psychiatric issues in dermatologic practice. Clin Dermatol. 2013;31:3-10.

8. Reister G, Tress W, Schepank H, Manz R, Sollors-Mossler B. The epidemiology of psychogenic disorders and consequences for prevention. Psychother Psychosom. 1989;52:10-20.

9. Picardi A, Pasquini P, Abeni D, Fassone G, Mazzotti E, Fava GA. Psychosomatic assessment of skin diseases in clinical practice. Psychother Psychosom. 2005;74:315-22.

10. Vora R, Anjaneyan G, Diwan N, Singhal R. Psychodermatology: a review. Int J Med Sci Den Health. 2015;1:89-103.

11. Nguyen CM, Beroukhim K, Danesh MJ, Babikian A, Koo J, Leon A. The psychosocial impact of acne, vitiligo, and psoriasis: a review. Clin Cosmet Investig Dermatol. 2016;9:383-92.

12. van Cranenburgh OD, van Koulil S, Boonstra HE, Crijns MB, Evers AWM, Kemperman P, et al. Psychodermatology in the Netherlands: a network of psychosocial care providers. Acta Derm Venerol. 2016;96:145.

13. Senra MS, Wollenberg A. Psychodermatological aspects of atopic dermatitis. $\mathrm{Br}$ J Dermatol. 2014;170 Suppl 1:38-43.

14. Gupta MA, Gupta AK. Current concepts in psychodermatology. Curr Psychiatry Rep. 2014;16:449.

15. Egawa G, Weninger W, Ginhoux F. Pathogenesis of atopic dermatitis: a short review. Cogent Biol. 2015;1.

16. Brazzini B, Ghersetich I, Hercogova J, Lotti T. The neuro-immuno-cutaneousendocrine network: relationship between mind and skin. Dermatol Ther. 2003; 16:123-31.

17. Harden JL, Krueger JG, Bowcock AM. The immunogenetics of psoriasis: a comprehensive review. J Autoimmun. 2015;64:66-73.

18. Bruce SE, Yonkers KA, Otto MW, Eisen JL, Weisberg RB, Pagano M, et al. Influence of psychiatric comorbidity on recovery and recurrence in generalized anxiety disorder, social phobia, and panic disorder: a 12-year prospective study. Am J Psychiatry. 2005;162:1179-87.

19. Kessler RC, Chiu WT, Jin R, Ruscio AM, Shear K, Walters EE. The epidemiology of panic attacks, panic disorder, and agoraphobia in the National Comorbidity Survey Replication. Arch Gen Psychiatry. 2006;63:415-24.

20. Davidoff J, Christensen S, Khalili DN, Nguyen J, IsHak WW. Quality of life in panic disorder: looking beyond symptom remission. Qual Life Res. 2012;21:945-59.

21. Tohid H, Aleem D, Jackson C. Major depression and psoriasis: a psychodermatological phenomenon. Skin Pharmacol Physiol. 2016;29:220-30.

22. Colgecen E, Celikbilek A, Keskin DT. Cognitive impairment in patients with psoriasis: a cross-sectional study using the Montreal Cognitive Assessment. Am J Clin Dermatol. 2016;17:413-9.

23. Pedraz M, Martin-Velasco Al, Garcia-Marchena N, Araos P, Serrano A, RomeroSanchiz P, et al. Plasma concentrations of BDNF and IGF-1 in abstinent cocaine users with high prevalence of substance use disorders: relationship to psychiatric comorbidity. PloS One. 2015;10:e0118610.

24. Suliman S, Hemmings SM, Seedat S. Brain-derived neurotrophic factor (BDNF) protein levels in anxiety disorders: systematic review and meta-regression analysis. Front Integr Neurosci. 2013;7:55.

25. Ahmadalipour A, Sadeghzadeh J, Vafaei AA, Bandegi AR, Mohammadkhani R, Rashidy-Pour A. Effects of environmental enrichment on behavioral deficits and alterations in hippocampal BDNF induced by prenatal exposure to morphine in juvenile rats. Neuroscience. 2015;305:372-83.

26. Park MH, Chang KD, Hallmayer J, Howe ME, Kim E, Hong SC, et al. Preliminary study of anxiety symptoms, family dysfunction, and the brain-derived neurotrophic factor (BDNF) Val66Met genotype in offspring of parents with bipolar disorder. J Psychiatr Res. 2015;61:81-8.

27. Lembo S, Capasso R, Balato A, Cirillo T, Flora F, Zappia V, et al. MCP-1 in psoriatic patients: effect of biological therapy. J Dermatolog Treat. 2014;25:83-6.

28. Harden JL, Lewis SM, Pierson KC, Suarez-Farinas M, Lentini T, Ortenzio FS, et al. CARD14 expression in dermal endothelial cells in psoriasis. PloS One. 2014;9: e111255.

29. Oglodek EA, Szota AM, Just MJ, Mos DM, Araszkiewicz A. The MCP-1, CCL-5 and SDF-1 chemokines as pro-inflammatory markers in generalized anxiety disorder and personality disorders. Pharmacol Rep. 2015;67:85-9.
30. Perez-Ibave DC, Rodriguez-Sanchez IP, Garza-Rodriguez Mde L, Barrera-Saldana HA. Extrapituitary growth hormone synthesis in humans. Growth Horm IGF Res. 2014;24:47-53.

31. Song Y, Zhou D, Wang X. Increased serum cortisol and growth hormone levels in earthquake survivors with PTSD or subclinical PTSD. Psychoneuroendocrinology. 2008;33:1155-9.

32. Theoharides TC, Alysandratos KD, Angelidou A, Delivanis DA, Sismanopoulos N, Zhang B, et al. Mast cells and inflammation. Biochim Biophys Acta. 2012;1822: 21-33.

33. Zorrilla EP, Koob GF. The therapeutic potential of CRF1 antagonists for anxiety. Expert Opin Investig Drugs. 2004;13:799-828.

34. Lalmansingh AS, Uht RM. Estradiol regulates corticotropin-releasing hormone gene (crh) expression in a rapid and phasic manner that parallels estrogen receptor-alpha and -beta recruitment to a 3',5'-cyclic adenosine $5^{\prime}$-monophosphate regulatory region of the proximal crh promoter. Endocrinology. 2008;149: 346-57.

35. Baran A, Flisiak I, Jaroszewicz J, Swiderska M. Serum adiponectin and leptin levels in psoriatic patients according to topical treatment. J Dermatolog Treat. 2015;26:134-8.

36. Baran A, Flisiak I, Jaroszewicz J, Swiderska M. Effect of psoriasis activity on serum adiponectin and leptin levels. Postepy Dermatol Alergol. 2015;32:101-6.

37. Nakajima H, Nakajima K, Nagano Y, Yamamoto M, Tarutani M, Takahashi M, et al. Circulating level of chemerin is upregulated in psoriasis. J Dermatol Sci. 2010;60:45-7.

38. Voloshyna I, Mounessa J, Carsons SE, Reiss AB. Effect of inhibition of interleukin-12/23 by ustekinumab on the expression of leptin and leptin receptor in human THP-1 macrophages. Clin Exp Dermatol. 2016;41:308-11.

39. Aly DG, Abdallah IY, Hanafy NS, Elsaie ML, Hafiz NA. Elevated serum leptin levels in nonobese patients with psoriasis. J Drugs Dermatol. 2013;12:e25-9.

40. Chen YJ, Wu CY, Shen JL, Chu SY, Chen CK, Chang YT, et al. Psoriasis independently associated with hyperleptinemia contributing to metabolic syndrome. Arch Dermatol. 2008;144:1571-5.

41. Lakdawala N, Babalola 0 zrd, Fedeles F, McCusker M, Ricketts J, Whitaker-Worth $D$, et al. The role of nutrition in dermatologic diseases: facts and controversies. Clin Dermatol. 2013;31:677-700.

42. Cheung L, Fisher RM, Kuzmina N, Li D, Li X, Werngren O, et al. Psoriasis skin inflammation-induced microRNA-26b targets NCEH 1 in underlying subcutaneous adipose tissue. J Invest Dermatol. 2016;136:640-8.

43. Hafner S, Zierer A, Emeny RT, Thorand B, Herder C, Koenig W, et al. Social isolation and depressed mood are associated with elevated serum leptin levels in men but not in women. Psychoneuroendocrinology. 2011;36:200-9.

44. Sweeney CM, Tobin AM, Kirby B. Innate immunity in the pathogenesis of psoriasis. Arch Dermatol Research. 2011;303:691-705.

45. Chiu YG, Shao T, Feng C, Mensah KA, Thullen M, Schwarz EM, et al. CD16 (FcRgammallI) as a potential marker of osteoclast precursors in psoriatic arthritis. Arthritis Res Ther. 2010;12:R14.

46. Takahashi H, Tsuji H, Takahashi I, Hashimoto Y, Ishida-Yamamoto A, lizuka H. Prevalence of obesity/adiposity in Japanese psoriasis patients: adiposity is correlated with the severity of psoriasis. J Dermatol Sci. 2009;54:61-3.

47. Chimenti MS, Triggianese $P$, Botti E, Narcisi A, Conigliaro P, Giunta A, et al. S100A8/A9 in psoriatic plaques from patients with psoriatic arthritis. J Int Medical Res. 2016;44:33-7.

48. Ritchlin CT, Haas-Smith SA, Li P, Hicks DG, Schwarz EM. Mechanisms of TNF-alpha- and RANKL-mediated osteoclastogenesis and bone resorption in psoriatic arthritis. J Clin Invest. 2003;111:821-31.

49. Bilgic 0, Sivrikaya A, Toker A, Unlu A, Altinyazar C. Serum levels of TWEAK in patients with psoriasis vulgaris. Cytokine. 2016;77:10-3.

50. Kiatsurayanon C, Niyonsaba F, Smithrithee R, Akiyama T, Ushio H, Hara M, et al. Host defense (Antimicrobial) peptide, human $\beta$-defensin-3, improves the function of the epithelial tight-junction barrier in human keratinocytes. J Invest Dermatol. 2014;134:2163-73.

51. Postal M, Lapa AT, Sinicato NA, de Oliveira Pelicari K, Peres FA, Costallat LT, et al. Depressive symptoms are associated with tumor necrosis factor alpha in systemic lupus erythematosus. J Neuroinflammation. 2016;13:5.

52. Contoreggi C. Corticotropin releasing hormone and imaging, rethinking the stress axis. Nucl Med Biol. 2015;42:323-39.

53. Zhou C, Yu X, Cai D, Liu C, Li C. Role of corticotropin-releasing hormone and receptor in the pathogenesis of psoriasis. Med Hypotheses. 2009;73:513-5.

54. Caraffa A, Spinas E, Kritas SK, Lessiani G, Ronconi G, Saggini A, Antinolfi P, Pizzicannella J, Toniato E, Theoharides TC, Conti P. Endocrinology of the skin: intradermal neuroimmune network, a new frontier. J Biol Regul Homeost Agents. 2016;30:339-43.

55. Toriya M, Maekawa F, Maejima Y, Onaka T, Fujiwara K, Nakagawa T, et al. Longterm infusion of brain-derived neurotrophic factor reduces food intake and body weight via a corticotrophin-releasing hormone pathway in the paraventricular nucleus of the hypothalamus. J Neuroendocrinol. 2010;22:987-95. 
56. Yamagata S, Kageyama K, Akimoto K, Watanuki Y, Suda T, Daimon M. Regulation of corticotropin-releasing factor and urocortin $2 / 3$ mRNA by leptin in hypothalamic N39 cells. Peptides. 2013;50:1-7.

57. Zbytek B, Slominski AT. CRH mediates inflammation induced by lipopolysaccharide in human adult epidermal keratinocytes. J Invest Dermatol. 2007;127:730-2.

58. Bayatti N, Hermann $\mathrm{H}$, Lutz B, Behl C. Corticotropin-releasing hormone-mediated induction of intracellular signaling pathways and brain-derived neurotrophic factor expression is inhibited by the activation of the endocannabinoid system. Endocrinology. 2005;146:1205-13.
59. Stengel A, Rivier J, Tache Y. Modulation of the adaptive response to stress by brain activation of selective somatostatin receptor subtypes. Peptides. 2013;42: $70-7$ 